\title{
THE PETER SCOTT MEMORIAL FUND
}

This Fund, intended to commemorate the work of the late Dr Peter Scott, has been established in response to a demand voiced by many members of the College and numerous other colleagues and friends.

Dr Scott has been described as 'One of the founding fathers of the contemporary school of British forensic psychiatry and possibly its most outstanding member'. His immense contributions during his distinguished career as a clinician and teacher at the Institute of Psychiatry, member of Government advisory bodies, adviser to many individuals and organizations (including the Police and Probation Service) and as a highly original and perceptive author are too numerous to list in detail. He was Chairman of the Forensic Psychiatry Specialist Section of the Royal College of Psychiatrists and Chairman of a number of the College's Special Committees of Council, including committees which submitted evidence on the problems of Battered Wives, Battered Babies and Sexual Offences. Dr Scott's experience and expertise were unique and he was constantly in demand to lecture, provide guidance and advise.

The prime aim of the Memorial is to improve forensic psychiatry education and it is hoped that sufficient funds can be raised to finance an Annual Lectureship or Prize which will be associated with his name. The final decision on what form the Memorial will take depends on the amount raised.

Many have already given to the Fund. Further donations should be forwarded to the Secretary at I 7 Belgrave Square, London SW IX 8PG.
P. G. McGrath, Chairman
R. S. Bluglass, Secretary

Peter Scott Memorial Fund Appeal Committee 